\title{
Li-Hong Xu: a life of leading by example
}

\author{
Guest Editor \\ Adriana Predoi-Cross
}

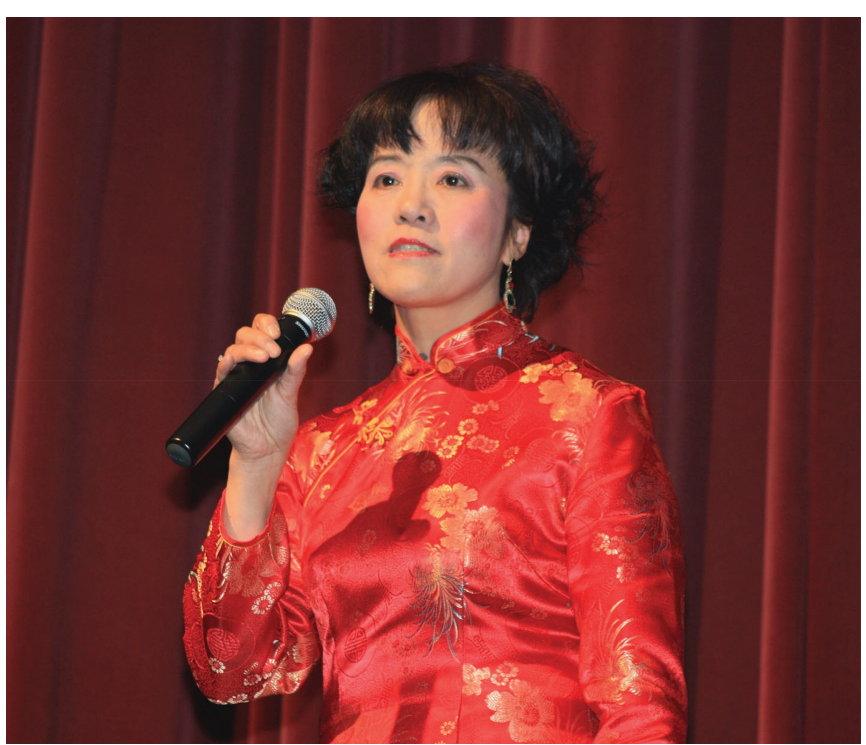

Professor Li-Hong Xu. @ 2019 Chinese Cultural Association of Saint John 